\title{
Specific molecular prenatal diagnosis for the CTG mutation in myotonic dystrophy
}

Jenny Myring, A Linda Meredith, Helen G Harley, Gertrude Kohn, Gail Norbury, Peter S Harper, Duncan J Shaw

\begin{abstract}
The results of DNA analysis for the specific mutation of myotonic dystrophy are reported in eight pregnancies (two studied retrospectively) in six families. Four results were normal; in the other four, large DNA expansions were found, comparable to the range seen in severely affected children with congenital onset of the disorder. The results agreed with those obtained by linked DNA markers in the six cases where they were available. We conclude that specific molecular prenatal diagnosis of myotonic dystrophy is feasible, and that an abnormal result may also give a guide to possible severity, though this should be interpreted with caution until greater experience is available.

( $\mathcal{F}$ Med Genet 1992;29:785-8)
\end{abstract}

Myotonic dystrophy is one of the most variable of the muscular dystrophies ${ }^{1}$ with severe and frequently fatal congenital onset of the disorder occurring in a proportion of offspring of affected women, ${ }^{2}$ while in the older generations subjects may have cataract and no significant neuromuscular abnormalities. Prenatal diagnosis of myotonic dystrophy has been feasible using linked DNA markers since the detection of close linkage with the $A P O C 2$ locus on chromosome $19,{ }^{34}$ but its application has been limited by a combination of factors, including inadequate family structure, uninformativeness of markers, and the possibility of inaccuracy from genetic recombination. ${ }^{5}$

The recent detection of an unstable CTG tandem repeat sequence as the basis for the mutation in myotonic dystrophy ${ }^{6-10}$ has, for the first time, provided the possibility of making a specific molecular prenatal diagnosis in this condition. We report here our initial experience with this and discuss the advantages and potential problems by comparison with the use of linked markers.

Summary of pregnancies studied.

\begin{tabular}{lllll}
\hline Family & Pregnancy & $\begin{array}{l}\text { Affected } \\
\text { parent }\end{array}$ & $\begin{array}{l}\text { Mutation } \\
\text { analysis }\end{array}$ & $\begin{array}{l}\text { Linkage } \\
\text { prediction }\end{array}$ \\
\hline 1 & 1 & Mother & $9 \mathrm{~kb}+\mathrm{E}$ & High \\
& $2(\mathrm{R})$ & Mother & $9 \mathrm{~kb}+\mathrm{E}$ & High \\
2 & $3(\mathrm{R})$ & Mother & $9 \mathrm{~kb}, 9 \mathrm{~kb}$ & Low \\
3 & 1 & Mother & $9 \mathrm{~kb}, 9 \mathrm{~kb}$ & Low \\
4 & 1 & Father & $9 \mathrm{~kb}, 10 \mathrm{~kb}$ & Not done \\
5 & 1 & Mother & $10 \mathrm{~kb}+\mathrm{E}$ & High \\
6 & 1 & Mother & $9 \mathrm{~kb}, 10 \mathrm{~kb}$ & Low \\
\hline
\end{tabular}

\section{Methods}

All prenatal diagnoses were undertaken on chorion villus samples taken between 9 and 12 weeks' gestation; blood samples were also taken from all relevant available family members. DNA was extracted from chorion villus samples and venous blood by standard methods. The DNA was digested to completion using the restriction enzyme EcoRI. The fragments were size fractionated by electrophoresis on $0.8 \%$ agarose gels run in TAE buffer $\mathrm{pH} 7.7$ (Tris- $\mathrm{HCl} 40 \mathrm{mmol} / \mathrm{l}$, glacial acetic acid $250 \mathrm{mmol} / \mathrm{l}$, EDTA $1 \mathrm{mmol} / \mathrm{l}$ ) at $1.4 \mathrm{~V} / \mathrm{cm}$ for 30 hours. The buffer was changed once during this time. Gels were blotted using Hybond $\mathrm{N}$, and hybridised using the ${ }^{32} \mathrm{P}$ labelled DNA probe pM10M6, which is a clone from the region D19S95 containing the unstable CTG sequence described by Harley et $a l^{6}$ and Brook et al..$^{10}$ The filters were washed down to $0.1 \times$ SSC and autoradiography carried out overnight. The probe pM10M6 detects an EcoRI polymorphism showing 9 and $10 \mathrm{~kb}$ fragments in the normal population; in myotonic dystrophy a band of variable size is seen resulting from the expansion of the $10 \mathrm{~kb}$ fragment by up to $6 \mathrm{~kb}$.

\section{Results}

The overall results of the study are summarised in the table. Of the eight pregnancies analysed (two retrospectively on stored DNA from earlier chorion biopsies), four were predicted to be affected, each with a clear expanded DNA sequence, while the remaining four samples showed no abnormality using restriction enzyme EcoRI.

\section{Case reports}

\section{FAMILY 1}

This family from Israel has already been mentioned briefly in a previous report. ${ }^{9}$ Two sisters, both moderately affected with myotonic dystrophy from late teenage years, requested prenatal diagnosis in a total of four pregnancies, the last occurring shortly after detection of the unstable CTG sequence.

The first pregnancy of the older sister had ended in the neonatal death of a congenitally affected child, an event which led to the diagnosis of myotonic dystrophy in the mother and other family members. In her subsequent two pregnancies prenatal diagnosis was requested and a low risk was predicted in both by the use of linked DNA markers on DNA from chorion biopsies. Healthy children without signs of myotonic dystrophy were subsequently born. 
The younger sister later requested prenatal diagnosis in her first pregnancy; a high risk was predicted by linked markers and the pregnancy was terminated. She again requested prenatal diagnosis in her second pregnancy, the CVS sample being received soon after the recognition of the CTG unstable sequence in myotonic dystrophy and before we had experience of its use in a diagnostic situation.

After considerable discussion it was decided to rely primarily on genetic linkage rather than on the hitherto untried specific mutation test; the closely linked marker D19S63 again predicted a high risk and the pregnancy was terminated on the basis of this report. DNA from this CVS sample was simultaneously analysed for the unstable sequence (fig 1) along with DNA from family members and residual CVS DNA from the previous high risk pregnancy. DNA available from one of the two low risk pregnancies of the sister was tested separately.

It can be seen that both high risk pregnancies show an abnormal band expanded by around $3 \mathrm{~kb}$, in the range found to be associated with severe disease ${ }^{9}$; the two mothers show abnormal bands of moderate size, while the affected grandfather also shows a small DNA expansion. No abnormal band was seen in the CVS sample from the pregnancy predicted to be at low risk (not shown in fig 1).

FAMILY 2

In this British family, referred from Birmingham by Dr Ian Glass, the affected mother already had two congenitally affected children and requested prenatal diagnosis in her third pregnancy. The mother shows a moderate
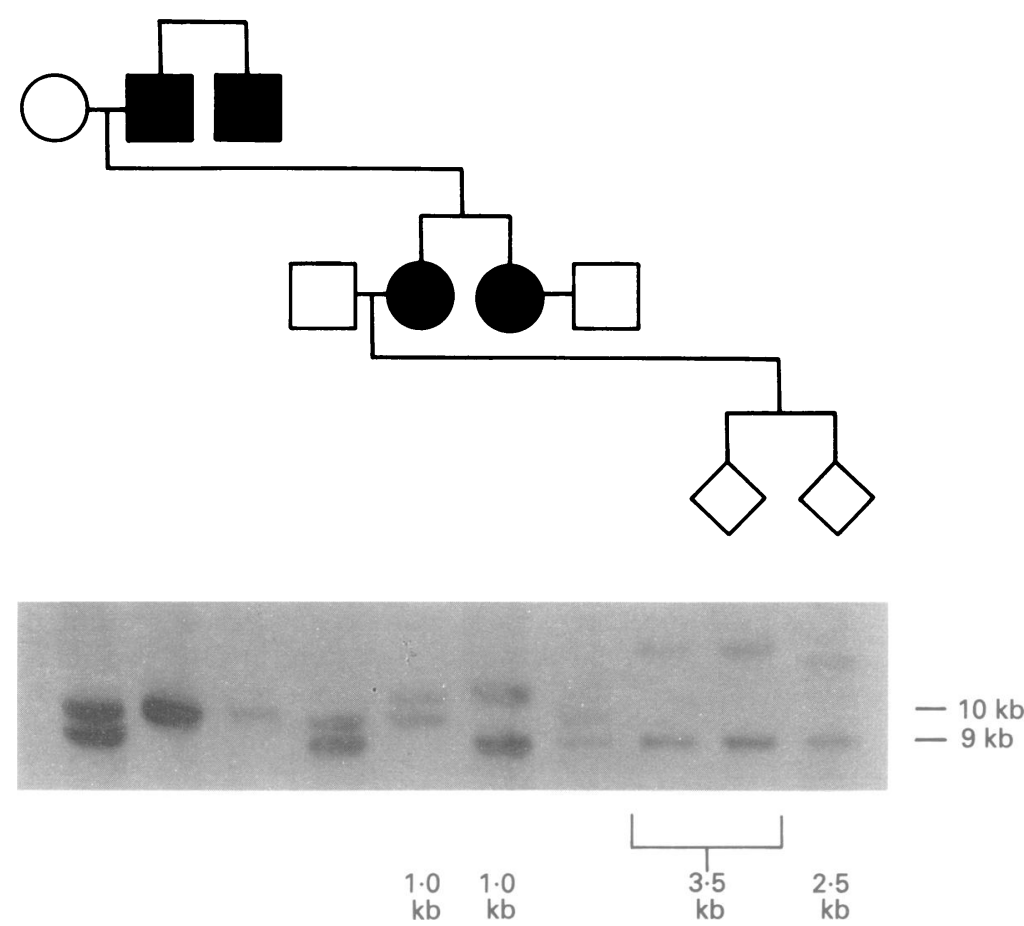

Figure 1 Family 1. Abnormal DNA expansions are present in the affected adult members of the family including the mother (lane 5), her sister (lane 6), and maternal grandfather (lane 2). A large expansion is present in both the previous affected pregnancy (lane 10) and the present pregnancy (lanes 8 and 9). The faintness of alleles in lanes 8 to 10 is from uneven lane loading owing to the minimal quantity of available DNA.
DNA expansion, while large expanded bands are present in the two congenitally affected children. The CVS sample shows a single $9 \mathrm{~kb}$ band, suggesting the fetus has received this allele from both parents (fig 2). There is no evidence of an expanded fragment. Linked markers also predicted a low risk and the pregnancy continues.

FAMILY 3

This family was referred by $\operatorname{Dr} M$ Zatz, São Paulo, Brazil. The healthy wife of a moderately affected man with myotonic dystrophy requested prenatal diagnosis and underwent chorion biopsy at $9 \frac{1}{2}$ weeks of pregnancy. Samples were sent by air to Cardiff and the results are shown in fig 3 . Both the proband and his affected brother show an abnormal expanded band, while the unaffected wife of the proband is homozygous for a normal $10 \mathrm{~kb}$ band. The fetus is heterozygous with normal 9 and $10 \mathrm{~kb}$ bands; the fact that it is the $9 \mathrm{~kb}$ band that has been received from the affected father makes it even less likely that the fetus would be affected, since in all cases studied so far, the expansion has been of a $10 \mathrm{~kb}$ band. ${ }^{6}$

\section{FAMILY 4}

In this British family the affected mother had already given birth to a severely affected child, and also had an affected sister and father. All affected members showed an expanded fragment, largest in the severely affected child. The CVS sample taken at 11 weeks' gestation showed an expanded band slightly larger than that of the severely affected sib. Linked markers also predicted an affected fetus and termination was carried out.

FAMILY 5

In this family, the affected mother had previously undergone prenatal diagnosis using linked probes (D19S63), the outcome of which
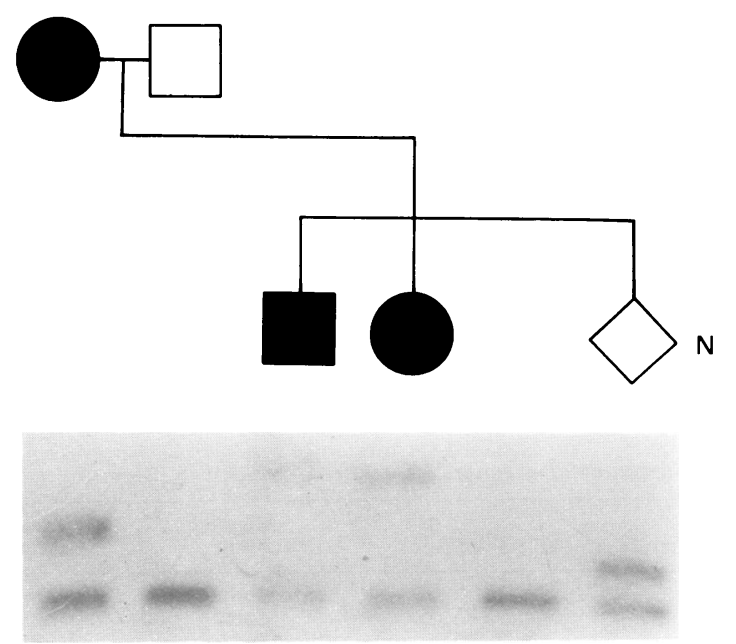

Figure 2 Family 2. A DNA expansion is present in the affected mother (lane 1), while the two congenitally affected children (lanes 3 and 4 ) show large expansions. affected children (lanes 3 and 4 ) show large expansi
The pregnancy shows a single $9 k b$ band, with no evidence of DNA expansion. A normal control (lane 6 ) shows normal heterozygous pattern. 


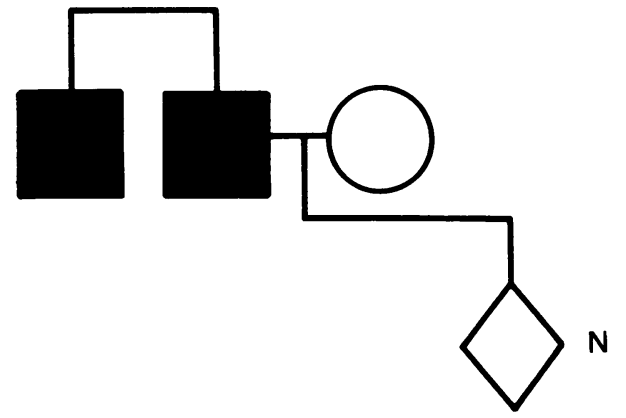

Figure 3 Family 3. Moderate sized DNA expansions are seen in the affected father (lane 2) and his affected brother (lane 1), both of whom also show a normal $9 \mathrm{~kb}$ band. The normal mother (lane 3) shows a normal $10 \mathrm{~kb}$ band only. The pregnancy (lane 4) shows normal sized 9 and $10 \mathrm{~kb}$ bands, similar to the normal control sample (lane 5).

was high risk. The current CVS was done at 10 weeks' gestation and together with appropriate family members was analysed for the mutation. Both the mother and her affected father had increased bands. The fetus showed a normal $10 \mathrm{~kb}$ fragment inherited from the unaffected heterozygous father and a $9 \mathrm{~kb}$ fragment, not associated with myotonic dystrophy, from the affected mother. Linked markers also gave a low risk result; the fetus was predicted to be at low risk and the pregnancy is continuing.

FAMILY 6 (FIG 4)

This family was referred after the deaths within two months of congenitally affected babies born to two affected female cousins. One cousin requested prenatal diagnosis during her second pregnancy. The affected grandfather showed a minimal expansion, the affected mother having a moderately increased band, while a large band (approximately $3 \mathrm{~kb}$ ) similar in size to that seen in the dead sib was present in the chorion biopsy; an affected fetus was predicted and the pregnancy terminated.

\section{Discussion}

The autosomal dominant inheritance and marked variation in severity seen in myotonic dystrophy mean that a mildly affected parent may have a significant risk of a severely affected child. This is particularly the case for the offspring of affected women, which comprise all but one of the pregnancies in this series for which prenatal diagnosis was requested. The overall risk of a severely affected child has been shown by Koch et $a l^{2}$ to be around $10 \%$, with a risk of around $40 \%$ when the mother has already had a child with congenital myotonic dystrophy. The risk of a severely affected child was also shown to be related to the clinical status of the affected mother, being greater for mothers with more severe disease, whereas congenital myotonic dystrophy was not seen where the mother was neurologically normal.

The cases described here show that the unstable CTG sequence specific for myotonic dystrophy can be detected in chorion villus and fetal samples. No ambiguity of interpretation was encountered in any of the eight pregnancies analysed (two retrospectively), while the result agreed with genetic linkage prediction in the six cases where this could be undertaken. No 'smearing' of DNA was encountered to suggest that somatic instability might particularly occur in chorionic tissue. (Preliminary unpublished data on blood samples suggest that this phenomenon may be age related and thus not likely to occur in the fetus.)

The four abnormal CV samples detected in three families all showed large DNA expansions in the range found most frequently in patients with congenital onset, and not encountered in mild or minimal disease. ${ }^{910}$ This is consistent with the fact that in the families concerned the mother was the affected parent; in two (families 4 and 6) the mother had previously had a seriously affected child, while in the other (family 1) the mother's sister, who was similarly affected, had lost a child with congenital myotonic dystrophy.

The possibility of predicting phenotype as well as genotype in prenatal diagnosis by DNA analysis is important, especially in an exceptionally variable disorder such as myotonic dystrophy, where subjects may be mildly or severely affected. Severity may be as important as numerical risk in determining parental decisions on terminating or continuing a pregnancy. Further experience will be required before we know the limits of accuracy in prediction of severity; in early termination after first trimester diagnosis it is rarely feasible to analyse muscle for signs of disease, while the immature appearance of muscle in congenitally affected patients would in any case make findings difficult to interpret in a fetal sample.

All the families with affected pregnancies in this series illustrate the phenomenon of anticipation, showing progressively earlier onset and greater severity in successive generations. ${ }^{11}$ This can now be explained in terms of progressive DNA expansion, as shown in figs 1 and 4 , though it is likely that an additional maternal factor is also operating in the congenital form of the disease.

The pregnaricies in this series found to be normal are currently continuing. Where linked markers could also be applied (families 2 and 5) these predicted a low risk. In family 2 the mother had previously had two congenitally affected children, making it likely that, had this fetus been affected, it too would have been severely affected and would have shown a large DNA expansion comparable to that of the previous child (fig 2), whereas in fact a normal $9 \mathrm{~kb}$ band pattern was seen.

One fetus predicted to be unaffected had an affected father (fig 3 ) and was thus not at risk of being congenitally affected. Again no abnormal band was seen, the pregnancy showing a 
normal heterozygous pattern with both a $9 \mathrm{~kb}$ and $10 \mathrm{~kb}$ band. This pattern allows a confident prediction of normality since it can be seen that the $9 \mathrm{~kb}$ band has been received from the affected father and the $10 \mathrm{~kb}$ band from the normal mother; invariably the myotonic dystrophy mutation is present on chromosomes with the $10 \mathrm{~kb}$ allele.

In none of the pregnancies was an accurate determination of copy number of the repeat sequence made using PCR based analysis. Normal subjects have been shown to have up to 30 copies of the CTG repeat sequence, while in minimally affected patients with myotonic dystrophy over 50 copies are present. ${ }^{10}$ Large expansions are not detectable by PCR which would thus have been unhelpful in the detection of the large or moderate DNA expansion expected and found in the abnormal cases described here. Minimally affected sibs of congenital cases are exceptional, ${ }^{12}$ and in both paternal and maternal transmission expansion of the unstable CTG repeat sequence is much more common than reduction in size, though we have occasionally observed the latter (Harley et al, in preparation). It seems likely that Southern blotting will detect almost all clinically significant cases of myotonic dystrophy. In minimally affected older patients with myotonic dystrophy the DNA expansion may be difficult to distinguish from the normal $10 \mathrm{~kb}$ allele using EcoRI and in such circumstances it can be more easily seen using probe pM10M6 with a PstI digest. Small expansions of $100 \mathrm{bp}$ upwards can be seen using this method although larger expansions may be difficult to assess accurately owing to smearing of the band which results from somatic instability. For detecting large expansions, which would usually be expected during prenatal diagnosis, an EcoRI digest is preferable.

The implication of detecting a minimal expansion should be discussed in genetic counselling before testing. In our experience
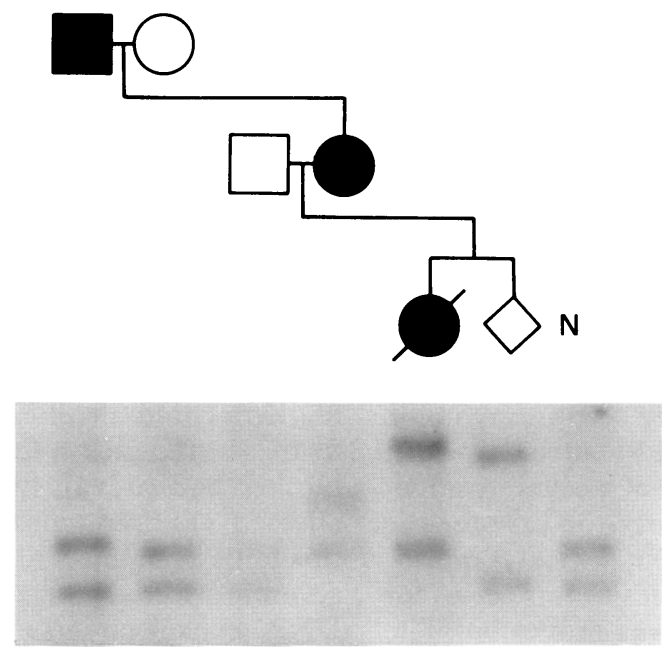

Figure 4 Family 6. DNA expansion is present in the affected adults (lanes 1 and 4), while the normal father (lane 3) and normal control (lane 7) are heterozygous, with normal 9 and $10 \mathrm{~kb}$ bands. The congenitally affected child (lane 5) shows a large DNA expansion, as does the pregnancy (lane 6). most families requesting prenatal diagnosis are concerned with the avoidance of clinically significant disease in a child, especially of congenital or severe childhood onset.

In all the families studied here, DNA was available for testing from one or more affected family members to ensure that a detectable specific DNA expansion was present in the family. The importance of such analysis should be emphasised, since it is still possible that occasional cases of the disease may prove to have a different mutational basis.

Finally, it should be remembered that closely linked DNA markers have provided a means of prenatal diagnosis for some years ${ }^{45}$ and it would seem wise to continue to use these as a check on results until experience with analysis of the specific mutation is greater. However, it seems likely that in the future, the specific mutational approach described here will supersede linkage in view of its applicability to all families, regardless of pedigree structure, the avoidance of error from recombination and need for computational analyses, as well as the information that it seems likely to give regarding severity of phenotype. A close parallel can be seen with the diagnostic use of the fragile $\mathrm{X}$ unstable DNA sequence, which is also proving of wide application. ${ }^{13}$

We thank the clinicians and laboratories who referred families, in particular Dr Ian Glass (Birmingham), Professor Mayana Zatz (Brazil), and Professor $\mathrm{H}$ Zakut (Israel). We also thank Dr Fiona MacDonald for undertaking analysis of linked markers in family 2 . Our work is supported by grants from the Muscular Dystrophy Group of Great Britain, the Muscular Dystrophy Association of America, the Medical Research Council, and the Wellcome Trust.

1 Harper PS. Myotonic dystrophy. London: Saunders, 1989

2 Koch MC, Grimm T, Harley HG, Harper PS. Genetic risks for children of women with myotonic dystrophy. $A m \mathcal{F}$ Hum Genet 1991;48:1084-91.

3 Shaw DJ, Meredith AL, Sarfarazi M, et al. The apolipoprotein CII gene: subchromosomal localisation and linprotein to the myotonic dystrophy locus. Hum Genet 1985;70:271-3.

4 Meredith AL, Huson SM, Lunt PW, et al. Application of a closely linked polymorphism of restriction fragment length to counselling and prenatal testing in families with length to counselling and prenatal testing in fam

5 Norman AM, Floyd JL, Harper PS. Presymptomatic detection and prenatal diagnosis for myotonic dystrophy by tion and prenatal diagnosis for myotonic dystrophy by

6 Harley HG, Brook JD, Rundle SA, et al. Expansion of an unstable DNA region and phenotypic variation in myotonic dystrophy. Nature 1992;355:454-6.

7 Buxton J, Shelbourne P, Davies J, et al. Detection of an unstable fragment of DNA specific to individuals with myotonic dystrophy. Nature 1992;335:547-8.

8 Aslanidis C, Jansen G, Amemiya C, et al. Cloning of the essential myotonic dystrophy region and mapping of the putative defect. Nature 1992;255:548-51.

9 Harley HG, Rundle SA, Reardon W, et al. Unstable DNA sequence in myotonic dystrophy. Lancet 1992;339:1125-8.

10 Brook JD, McCurrach ME, Harley HG, et al. Molecular basis of myotonic dystrophy: expansion of a trinucleotide CTG) repeat at the $3^{\prime}$ end of a transcript encoding a protein kinase family member. Cell 1992;68:799-808.

11 Harper PS, Harley HG, Reardon W, Shaw DJ. Anticipation in myotonic dystrophy: new light on an old problem. Am $\mathcal{F}$ Hum Genet 1992;51:10-16.

12 O'Brien T, Newcombe RG, Harper PS. Outlook for a clinically normal child in a sibship with congenital myotonic dystrophy. $\mathcal{F}$ Pediatr 1983;103:762-3.

13 Sutherland GR Gedeon A, Kornman L, et al. Prenatal dierland GR, Gedeon A, Kornman L, et al. Prenatal diagnosis of fragile $X$ syndrome by direct detection of the characteristic unstable DNA sequence. $N$ Engl $\mathcal{F} \mathrm{Med}$ 